\title{
HSV-TK/GCV can induce cytotoxicity of retinoblastoma cells through autophagy inhibition by activating MAPK/ERK
}

\author{
QUAN-YONG YI ${ }^{1 *}$, ZHI-SHA BAI $^{1 *}$, BIN CAI $^{2 *}$, NAN CHEN $^{3}$, LI-SHUANG CHEN $^{1}$, \\ TAO YUAN ${ }^{1}$ and JING-HAI MAO ${ }^{1}$ \\ ${ }^{1}$ Department of Ophthalmology, Ningbo Eye Hospital; ${ }^{2}$ Ningbo Central Blood Center, Ningbo, Zhejiang 315040; \\ ${ }^{3}$ Department of Ophthalmology, The Fourth Affiliated Hospital of Guangzhou Medical University, \\ Guangzhou, Guangdong 510000, P.R. China
}

Received October 31, 2017; Accepted May 9, 2018

DOI: $10.3892 / o r .2018 .6454$

\begin{abstract}
Retinoblastoma is an severe ophthalmic disease and the most common type intraocular malignant tumor, particularly in infants. Currently, few drugs and therapies are available. Gene therapy has been considered to be a potential treatment to cure cancer effectively and Herpes simplex virus type 1 thymidine kinase/ganciclovir (HSV-TK/GCV) is one type of suicide gene therapy that has been extensively studied. Numerous in vitro and in vivo studied have shown that this system can kill tumor cells, including liver and lung cancer cells. GCV is used as an antiviral drug, and the thymidine kinase, HSV-TK can phosphorylate GCV to GCV-TP, a competitive inhibitor of DNA synthesis, instead of guanine-5'-triphosphate in the process of DNA synthesis. This process prevents DNA chain elongation causing cell death via apoptosis. However, the toxic effects of HSV-TK/GCV on retinoblastoma cells remain unknown, and the molecular mechanisms of its therapeutic effects have not been fully elucidated. Our results suggest that $\mathrm{HSV}-\mathrm{TK} / \mathrm{GCV}$ can significantly cause the death of retinoblastoma cell lines, HXO-RB44 and Y79. Further studies have reported that this cell death is induced by the inhibition of autophagy by activating the MAPK/ERK (mitogen-activated protein kinase/ERK) signaling pathway. The mTOR inhibitor Torin1 can partially block the toxic effects of HSV-TK/GCV on HXO-RB44 cells. The above results demonstrate that the mechanism undertaken by
\end{abstract}

Correspondence to: Dr Quan-Yong Yi,Department of Ophthalmology, Ningbo Eye Hospital, 855 Minan Road, Ningbo, Zhejiang 315040, P.R. China

E-mail: quanyong_yi@163.com

*Contributed equally

Abbreviations: HSV-TK, herpes simplex virus type 1 thymidine kinase; GCV, ganciclovir; MAPK, mitogen-activated protein kinase; Baf A1, bafilomycine A1; GCV-DP, bisphosphonates-GCV; GCV-TP, triphosphate-GCV

Key words: HSV-TK/GCV, cytotoxicity, retinoblastoma, autophagy, MAPK/ERK
HSV-TK/GCV to exhibit therapeutic effects mechanism may inhibit autophagy by activating MAPK/ERK. The findings of the present study may provide novel insight for the exploration of HSV-TK/GCV in the treatment of retinoblastoma.

\section{Introduction}

Retinoblastoma (RB) is a severe ophthalmic disease. It is the most common type of intraocular malignant tumor among infants and damages eyesight, ophthalmic tissues and reduces quality of life. As an embryonic malignant tumor, RB originates from the primitive nuclear stem cells of the nuclear layer of the retina. It accounts for $4 \%$ of childhood malignant tumors (1). This disease can lead to impaired vision and blindness (2). At present, there are mainly three treatments for RB as follows: Topical, surgical and systemic. Topical treatment, including cryotherapy, laser photocoagulation, transpupillary thermotherapy, local radiotherapy, external radiation therapy may be applied to rescue the eyeball by direct destruction of the tumor. Systemic chemotherapy is widely applied in the systemic therapy of RB. Surgical treatment mainly refers to the enucleation of eyeballs and orbital exenteration surgery (3-8). These therapies have notable side effects and defects; however, there is still no effective method and medication to treat RB. Gene therapy is considered to be a potential cure of the disease (9-12). Suicide gene therapy against tumor cells results in the expression of a metabolic enzyme gene through transgenic manipulation; the expressed metabolic enzyme can convert non-toxic compounds (prodrug) into cytotoxic drugs that can kill cells, thereby tumor cells are eliminated selectively (13-15).

The Herpes simplex virus type 1 thymidine kinase (HSV-TK)/ganciclovir (GCV) system has been employed in extensive studies, and is also the most widely studied suicide gene. HSV-TK is a specific product of type $1 \mathrm{HSV}(16,17)$. HSV-TK can phosphorylate GCV to bisphosphonates-GCV (GCV-DP) and triphosphate-GCV (GCV-TP); GCV-TP is a competitive inhibitor of DNA polymerase that can terminate DNA chain elongation and eventually cause cell death, thereby inducing mammalian cell toxicity (18). The HSV-TK/GCV system also leads to irreparable DNA breaks and inhibits the homologous repair of genes, greatly 
enhancing cytotoxicity $(18,19)$. When HSV-TK-transfected and HSV-TK-negative cells were co-cultured and treated with GCV, HSV-TK-positive cell apoptosis was detected; however, apoptosis may be induced in HSV-TK-negative cells. The bystander effect further suggests that the HSV-TK/GCV system may exhibit notable antitumor effects $(20,21)$. However, the exact molecular mechanisms underlying the antitumor effects of the HSV-TK/GCV system have not been elucidated; in particular, the antitumor mechanism of $\mathrm{RB}$ requires more detailed research and further investigation.

Autophagy is a specific cell response to a range of stressors, including nutritional deficiency, growth factor deprivation or other genetic mutations-induced stresses (22-24). This process constitutes the degradation of endogenous proteins within lysosomes to remove damaged old organelles, such as damaged mitochondria, and contributes to the maintenance of cell self-renewal and homeostasis $(22,25)$. The 2016 Nobel Prize in Physiology or Medicine was awarded to cell biologist Yoshinori Ohsumi, who identified and characterized the autophagy machinery in yeast in 1993 (26). Numerous studies have shown that autophagy is associated with many diseases, including neurodegenerative diseases (27), autoimmunity (28), heart (29) and metabolic diseases (30) and cancer (31). In recent years, autophagy has been reported to serve an important role in tumor formation, proliferation, and migration (32-36). Autophagy inhibitors, such as chloroquine, have demonstrated marked antitumor effects in breast, colon, and non-small cell lung cancers (37-40). Therefore, the present study aimed to investigate whether the HSV-TK/GCV system may serve an antitumor role in human retinal tumor cells and this role may be mediated by autophagy. In the present study, we transfected HSV-TK into two retinal tumor cell lines and then treated with GCV. The results revealed that HSV-TK/GCV may induce notable retinal tumor cell cytotoxicity. Additionally, our results also showed that HSV-TK/GCV did not inhibit autophagy by classic mTOR pathways. It was reported that the MAPK signaling pathway is closely associated with autophagy (41). This indicated that HSV-TK/GCV may induce cell cytotoxicity by affecting autophagy through the MAPK/ERK signaling pathway. The findings of the present study also revealed that HSV-TK/GCV may significantly enhance the levels of phospho-ERK1/2, suggesting that cell cytotoxicity induced by HSV-TK/GCV may inhibit autophagy via the activation of MAPK/ERK.

In conclusion, our results indicated that HSV-TK/GCV could notably induce the cytotoxicity of RB cells, and its molecular mechanism may affect autophagy by activating MAPK/ERK. These results may provide novel insights for the advanced treatment of retinal tumors via an optimized HSV-TK/GCV system.

\section{Materials and methods}

Plasmid constructs. To generate pLenO-GTP-HSV-TK, the HSV-TK oligonucleotides were synthesized according to GenBank (gene ID: 1487307), and then cloned to lentivirus vector pLenO-GTP via EcoRI and BamHI; mCherry-hLC3B-pcDNA3.1 was a gift from David Rubinsztein (Addgene plasmid cat. no. 40827) (42), and this plasmid was transfected into 293 cells to observe the effect of
HSV-TK/GCV system on autophagic flux. All plasmids were confirmed by sequencing (The Beijing Genomics Institute, Beijing, China).

Lentiviral particles preparation. Transient production of the lentiviral vector particles was conducted in 293 cells by transfecting vector plasmid pLenO-GTP-HSV-TK, generation packaging plasmids and envelope glycoprotein pRsv-REV, pMDlg-pRRE and pMD2G. After $72 \mathrm{~h}$, supernatants containing viral particles were harvested and centrifuged at $4,000 \mathrm{x} \mathrm{g}$ at $4^{\circ} \mathrm{C}$ for $10 \mathrm{~min}$. The supernatant was filtered with a $0.45-\mu \mathrm{m}$ membrane and then centrifuged at $25,000 \mathrm{x}$ g at $4^{\circ} \mathrm{C}$ for $2 \mathrm{~h}$. The lentiviral particles were suspended with ice-cold DMEM and stored at $-80^{\circ} \mathrm{C}$.

Cell culture, transfection and drugs. Retinoblastoma cell lines HXO-RB44 and Y79 were cultured in RPMI-1640 Medium (Gibco; Thermo Fisher Scientific, Inc., Waltham, MA, USA) containing 10\% fetal bovine serum (FBS) (Gibco; Thermo Fisher Scientific, Inc.) with penicillin (100 U/ml) and streptomycin (100 g/ml). 293 and HeLa cells were cultured in Dulbecco's modified Eagle's medium (DMEM; Gibco; Thermo Fisher Scientific, Inc.) containing 10\% fetal bovine serum (FBS; Gibco; Thermo Fisher Scientific, Inc.) with penicillin $(100 \mathrm{U} / \mathrm{ml})$ and streptomycin $(100 \mathrm{~g} / \mathrm{ml})$. To obtain expressing HSV-TK HXO-RB44 cells, HXO-RB44 cells were transfected with HSV-TK (pLenO-GTP-HSV-TK). After $48 \mathrm{~h}$ post-transfection, the medium was replaced with RPMI-1640 containing penicillin $(100 \mathrm{U} / \mathrm{ml})$, streptomycin $(100 \mathrm{~g} / \mathrm{ml})$ and puromycine $(4 \mu \mathrm{g} / \mathrm{ml}) .293$ and HeLa cells were purchased from the American Type Culture Collection (ATCC; Manassas, VA, USA); Y79 and HXO-RB44 retinoblastoma cell line were obtained from Shanghai Ninth People's Hospital (Shanghai, China). The HSV-TK positive cells were treated with GCV at $0,10,20$ or $40 \mu \mathrm{g} / \mathrm{ml}$. GCV was purchased from Sigma-Aldrich, ERK inhibitor U0126 was purchased from Selleck Chemicals (Houston, TX, USA), Bafilomycine A1 and Torin1 were purchased from Cell Signaling Technology, (Danvers, MA, USA). To investigate the effect of HSV-TK/GCV system on autophagic flux, HSV-TK positive HXO-RB44 cells were pretreated with Torin1 $(250 \mathrm{nM})$ or Baf A1 (100 nM) for $12 \mathrm{~h}$ at room temperature, subsequently treated with GCV at $20 \mu \mathrm{g} / \mathrm{ml}$ for $48 \mathrm{~h}$. To investigate effects of ERK inhibitor U0126 on HSV-TK/GCV system, HSV-TK positive HXO-RB44 cells were pretreated with U0126 $(10 \mu \mathrm{M})$ for $4 \mathrm{~h}$ at room temperature and subsequently treated with $\mathrm{GCV}$ at $20 \mu \mathrm{g} / \mathrm{ml}$ for $48 \mathrm{~h}$, and then the cell viability was measured by MTT and compare with the control group that no treatment with inhibitor.

Immunoblot analysis. He cells were harvested after transfection $48 \mathrm{~h}$, treated with GCV and were lysed in cell lysis buffer [25 mM Tris-HCl (pH 7.6), 1\% NP-40, $150 \mathrm{mM} \mathrm{NaCl}$ and $1 \%$ sodiumdeoxycholate]; a protease inhibitor cocktail was also applied (Roche Diagnostics, Basel, Switzerland). The proteins were separated by SDS-PAGE and then transferred onto a polyvinylidene difluoride membrane (Millipore) for immunoblotting. Immunoblot analysis was performed with the following primary antibodies: Monoclonal anti-p62 (1:500; cat. no. ab56416), polyclonal anti-LC3 
(1:5,000; cat. no. ab51520) was purchased from Abcam (Cambridge, UK), monoclonal anti-GAPDH (1:20,000; cat. no. MAB374) was purchased from Millipore, polyclonal anti-phospho-p70S6K antibody (1:1,000; cat. no. 9234), anti-p70S6K (1:1,000; cat. no. 2708), anti-phospho-Erk1/2 (1:1,000; cat. no. 4370), anti-Erk1/2 (1:1,000; cat. no. 4695), anti-phospho-p38 (1:1,000; cat. no. 4511), anti-p38 (1:1,000; cat. no. 8690), anti-phospho-JNK1/2 (1:500; cat. no. 4668), anti-JNK1/2 (1:500; cat. no. 9252), anti-phospho-mTOR (1:300; cat. no. 5536), anti-mTOR (1:300; cat. no. 2983), anti-AMPK (1:1,000; cat. no. 5832), anti-phospho-AMPK (1:1,000; cat. no. 2535) antibody were purchased from Cell Signaling Technology, Inc.

Cell imaging. 293 cells were washed with pre-warmed PBS and then fixed with $4 \%$ paraformaldehyde in PBS at room temperature for $5 \mathrm{~min}$, the cells were observed using fluorescence microscopy (Nikon). HeLa cells transfected with HSV-TK and treated with GCV were observed 24 or $48 \mathrm{~h}$ later using fluorescence microscopy (Nikon).

Cell death and viability assay. HSV-TK-positive RB cells HXO-RB44 and Y79 were treated with GCV and analyzed with an MTT assay as follows: The cells were incubated with $0.5 \mathrm{mg} / \mathrm{ml}$ MTT [3-(4,5)-dimethylthiahiazo (-z-y1)-3,5-di-phenytetrazoliumromide, purchased from (Sigma-Aldrich; Merck KGaA)] at the concentration of $0.5 \mathrm{mg} / \mathrm{ml}$ in RPMI-1640 medium without phenol red for $3 \mathrm{~h}$ at room temperature. As HXO-RB44 and Y79 were in suspension, the cells were collected via centrifugation at 1,000 rpm for $5 \mathrm{~min}$; the media was then discarded. The cells were dissolved in dimethyl sulfoxide and subsequently centrifuged at 12,000 rpm for $5 \mathrm{~min}$. The optical density was measured with a photometer at $570 \mathrm{~nm}$, and background at $630 \mathrm{~nm}$ was subtracted. The quantitative data were normalized to the control that HSV-TK-negative cells not treated with GCV and the ratios are presented as the mean \pm standard error of the mean. All quantitative data were analyzed from three independent experiments.

Small interfering RNA (siRNA) transfection. The siRNA specific for Beclin1 (CUAAGGAGCUGCCGUUAUAUU), ATG5 (GGA AUAUCCUGCAGAAGAAUU) or control siRNA were purchased from Shanghai GenePharma Co., Ltd. (Shanghai, China) (43). Cells were transfected with siRNA using RNAiMAX (Invitrogen; Thermo Fisher Scientific, Inc.) according to the manufacturer's instructions. Cells were then subjected to immunoblot analysis after incubated for $48 \mathrm{~h}$.

Reverse transcription polymerase chain reaction (RT-PCR). Total RNA was extracted from cells using TRIzol reagent (Invitrogen) and reverse transcribed to complementary DNA according to the manufacturer's instructions (RR037; Takara). RT-PCR analysis was performed to identify whether HSV-TK was stably expressed in cells using a PCR detection system (Applied Biosystems). The cDNA was amplified by PCR as follows (50 $\mu \mathrm{l})$ (R005Q; Takara): cDNA template $50 \mathrm{ng}$; Pyrobest $^{\mathrm{TM}}$ DNA Polymerase $0.2 \mu \mathrm{l}$; dNTP mix $(0.5 \mathrm{mM}$ each); 10X Pyrobest Buffer II ( $\mathrm{Mg}^{2+}$ plus, $\left.10 \mathrm{mM}\right)$; primer $(0.5 \mu \mathrm{M})$; denaturation temperature: $95^{\circ} \mathrm{C}, 30 \mathrm{sec}$; annealing temperature $56^{\circ} \mathrm{C}, 30 \mathrm{sec}$; extension reaction: $72^{\circ} \mathrm{C}, 40 \mathrm{sec}$; 35 cycles. The products were separated on a $1 \%$ agarose gel and stained with ethidium bromide. The following primers were used: 5'-ATGACAAGCGCCCAGATA-3' and 5'-AGG GTAAATAACGTGTCC-3' for a 512 bp target sequence.

Statistical analysis. Statistical analyses were performed using a two-tailed Student's t-test for the comparison of two groups. The comparison of multiple groups were analyzed using one-way analysis of variance (ANOVA) or two-way ANOVA depending on comparison variables, followed by a Tukey's pot hoc analysis as indicated (GraphPad Prism 6; GraphPad Software, Inc., La Jolla, CA, USA). Data were expressed as the mean \pm standard deviation. $\mathrm{P}<0.05$ was considered statistically significant.

\section{Results}

HSV-TK is stably expressed in retinal tumor cells and other cells. We synthesized HSV-TK sequence fragments and cloned them into lentiviral vector for transfection into cells. The target gene was successfully constructed and identified by RT-PCR, restriction endonuclease-mediated identification and PCR sequencing (Fig. 1A and B).

Subsequently, plasmids containing HSV-TK were transfected to HXO-RB44 cells, and the effect of transfection was observed by fluorescence after 48 h (Fig. 1C). Simultaneously, to identify stable expression in cells, total RNA was extracted from the transfected cells, which revealed that the HSV-TK sequence can be detected via RT-PCR (Fig. 1D). These findings show that HSV-TK can be stably expressed in HXO-RB44 cells. Similar results were observed in other cells such as Y79, HeLa and 293 which were transfected with HSV-TK (data not shown). These results suggest that the HSV-TK constructed in the present study can be stably expressed in retinal tumor cell Y79 and other cells, including HeLa and 293, which may be used in future investigations.

HSV-TK/GCV can significantly induce retinal tumor cell death as well as other tumor cells. Many studies have reported that $\mathrm{HSV}-\mathrm{TK} / \mathrm{GCV}$ can induce the apoptosis of a variety of tumor cell types $(19,62)$. In this study, to investigate whether HSV-TK/GCV could also induce retinal tumor cell death, HSV-TK were transfected into the tumor cell line HXO-RB44, which was treated with GCV at 10, 20 or $40 \mu \mathrm{g} / \mathrm{ml}$ for 24 and $48 \mathrm{~h}$ respectively; cell viability was then detected with an MTT assay. The results demonstrated that after HSV-TK transfection, GCV treatment may significantly reduce cell viability and as time and GCV concentration increase (Fig. 2A and B). HSV-TK/GCV-inducing cell death was reported to be dependent on GCV concentration and time. However, the cell viability of the control group (without HSV-TK transfection) did not significantly decrease after GCV treatment (Fig. 2A and B). Similar results were also obtained in another retinal tumor cell line, Y79 (Fig. 2E). Additionally, HeLa cells transfected with HSV-TK and treated with GCV, exhibited significant induction of cell death (Fig. 2C and D). These results indicate that HSV-TK/GCV may significantly induce the apoptosis of retinal tumor cells and other types of tumor cells. 
A

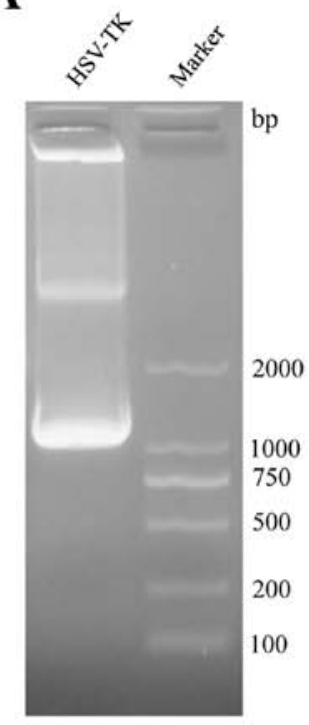

B

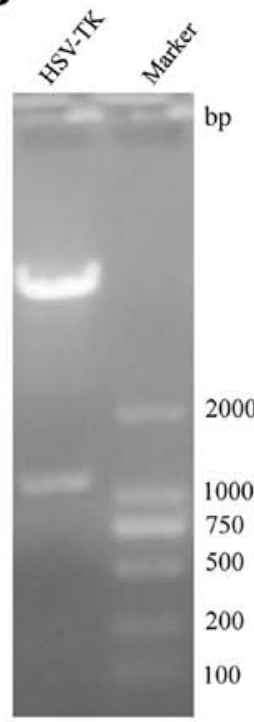

C

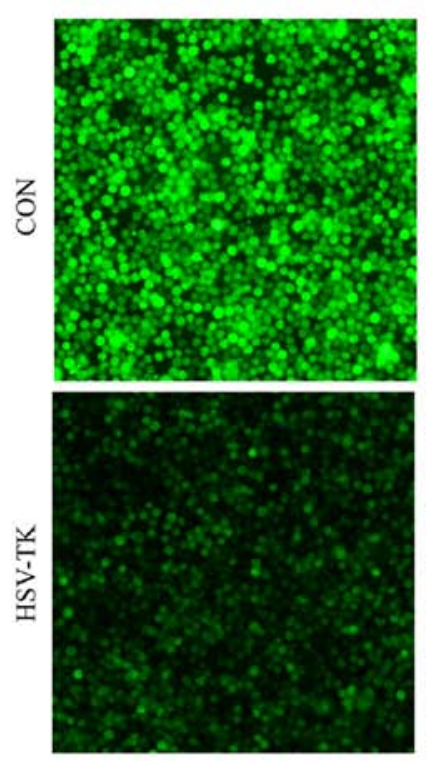

$\mathrm{PH}$

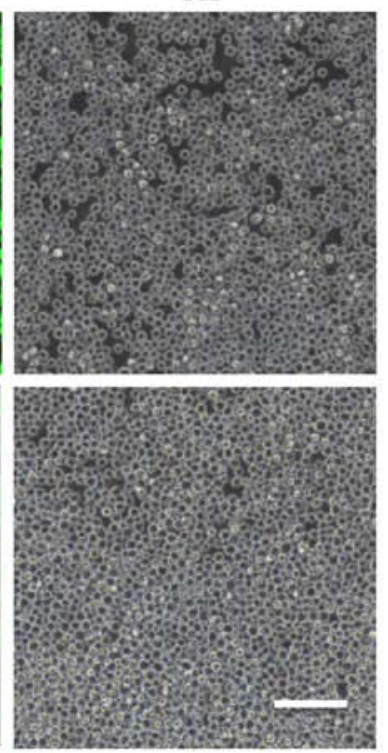

D

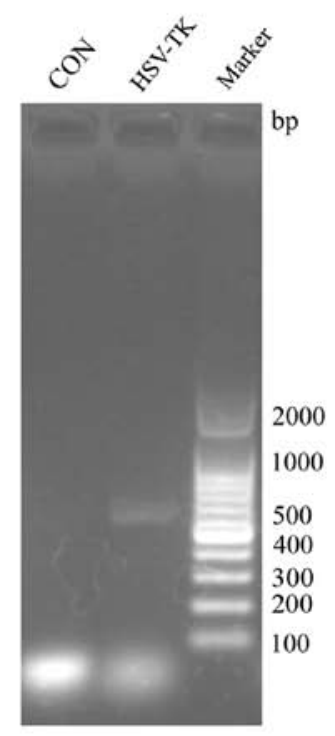

Figure 1. HSV-TK can be stably expressed in retinoblastoma cells and other cells in the present study. (A) The plasmid pLenO-GTP-HSV-TK was identified by PCR. (B) The plasmid pLenO-GTP-HSV-TK was identified by digested at EcoRI/BamHI. (C) HXO-RB44 cells were transfected with CON or HSV-TK. After $48 \mathrm{~h}$ post-transfection, the cells were observed. The positive cells colored green. (D) Total RNA was extracted from HXO-RB44 cells transfected CON (pLenO-GTP) or HSV-TK (pLenO-GTP-HSV-TK) after $48 \mathrm{~h}$. The HSV-TK RNA expression levels were analyzed with PCR. The scale bars indicate $50 \mu \mathrm{m}$. HSV-TK, Herpes simplex virus type 1 thymidine kinase; PCR, polymerase chain reaction.

HSV-TK/GCV can upregulate autophagy-associated proteins. Autophagy is important for maintaining cell growth and normal function (30). When autophagy is abnormal, the autophagic abnormalities may lead to cell dysfunction, such as protein degradation disorders, cell growth block or cell cycle changes (23-25). Therefore, the present study aimed to investigate whether retinal tumor cell death induced by HSV-TK/GCV may be mediated by autophagy. HSV-TK-positive HXO-RB44 cells were treated with $0,10,20$ or $40 \mu \mathrm{g} / \mathrm{ml} \mathrm{GCV}$ for 24 or $48 \mathrm{~h}$ respectively, the level of LC3 type 2 (LC3II) was significantly upregulated (Fig. 3A, C, D and F). The adaptor protein $\mathrm{p} 62 / \mathrm{SQSTM} 1$ is an autophagy substrate that is selectively degraded via autophagy and serves an important role in autophagy (44-47). The results show that p62 associated with autophagy also increased notably (Fig. 3A, B, D and E). The same results were observed in Y79 cells (Fig. 3G). To further explore the effects of HSV-TK/GCV on autophagy, the expression levels of LC3 type 2 were observed after ATG5 or Beclin1 knockdown in HXO-RB44 cells transfected with HSV-TK or non-transfected cells, and treated with or without GCV. Knockdown ATG5 in the HSV-TK positive HXO-RB44 cells, when the cytosolic LC3 type (LC3I) to autophagosomal membramne-LC3 (LC3II) prevented, the results showed that the cells treated with GCV resulted in a decrease in the expression levels of LC3II (Fig. 3H). In addition, the knockdown of Beclin1 in HXO-RB44 cells expressing HSV-TK revealed 
A

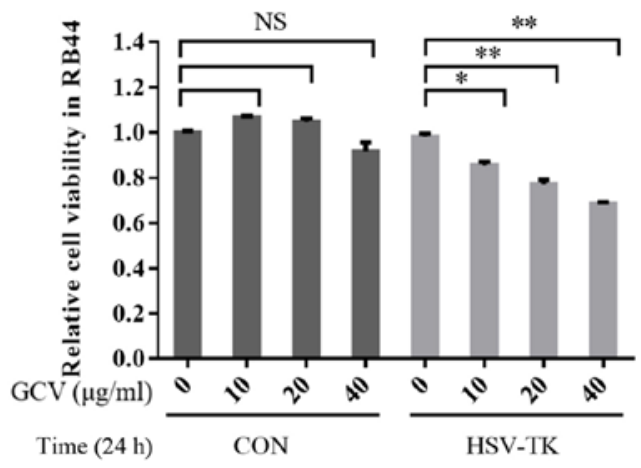

C

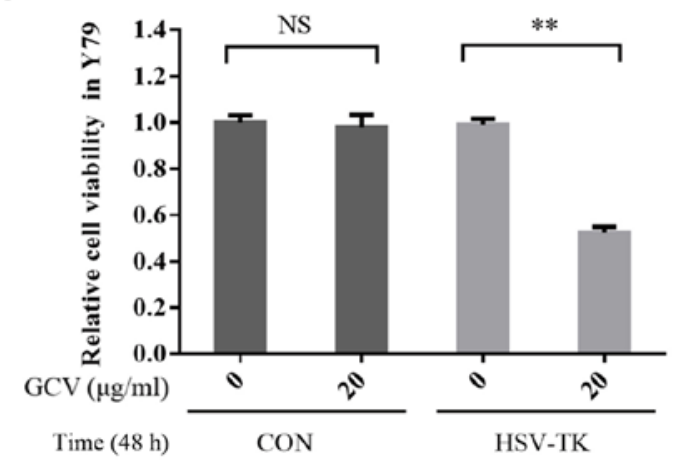

$\mathbf{E}$
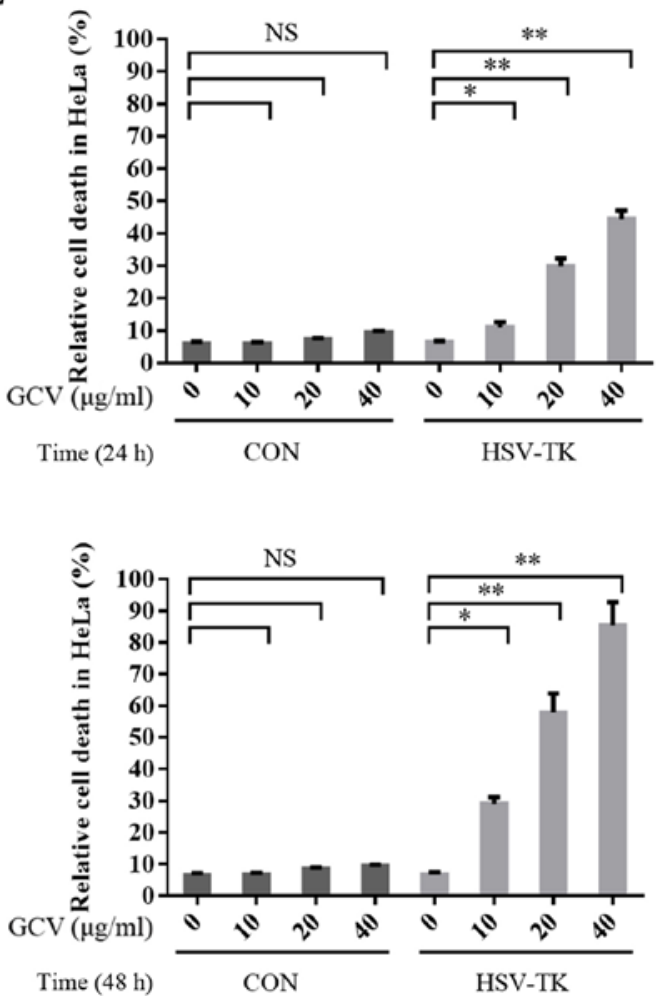

B

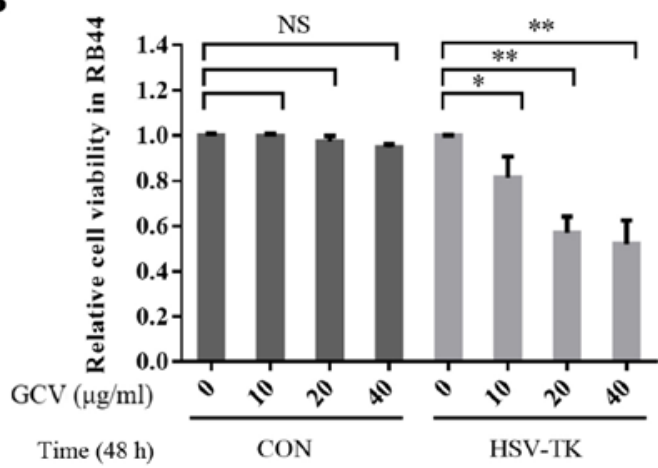

D

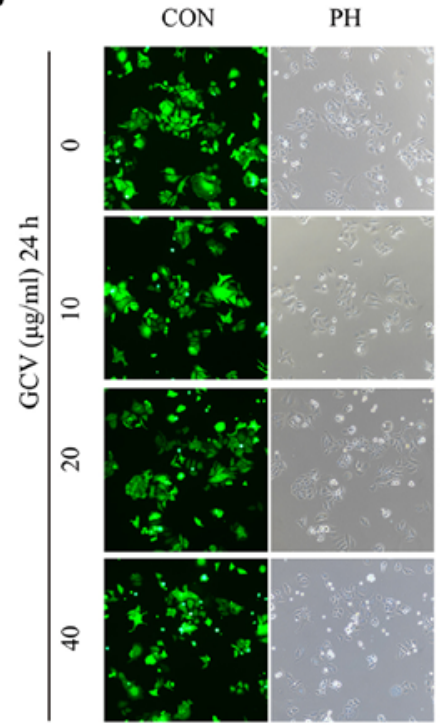

HSV-TK PH
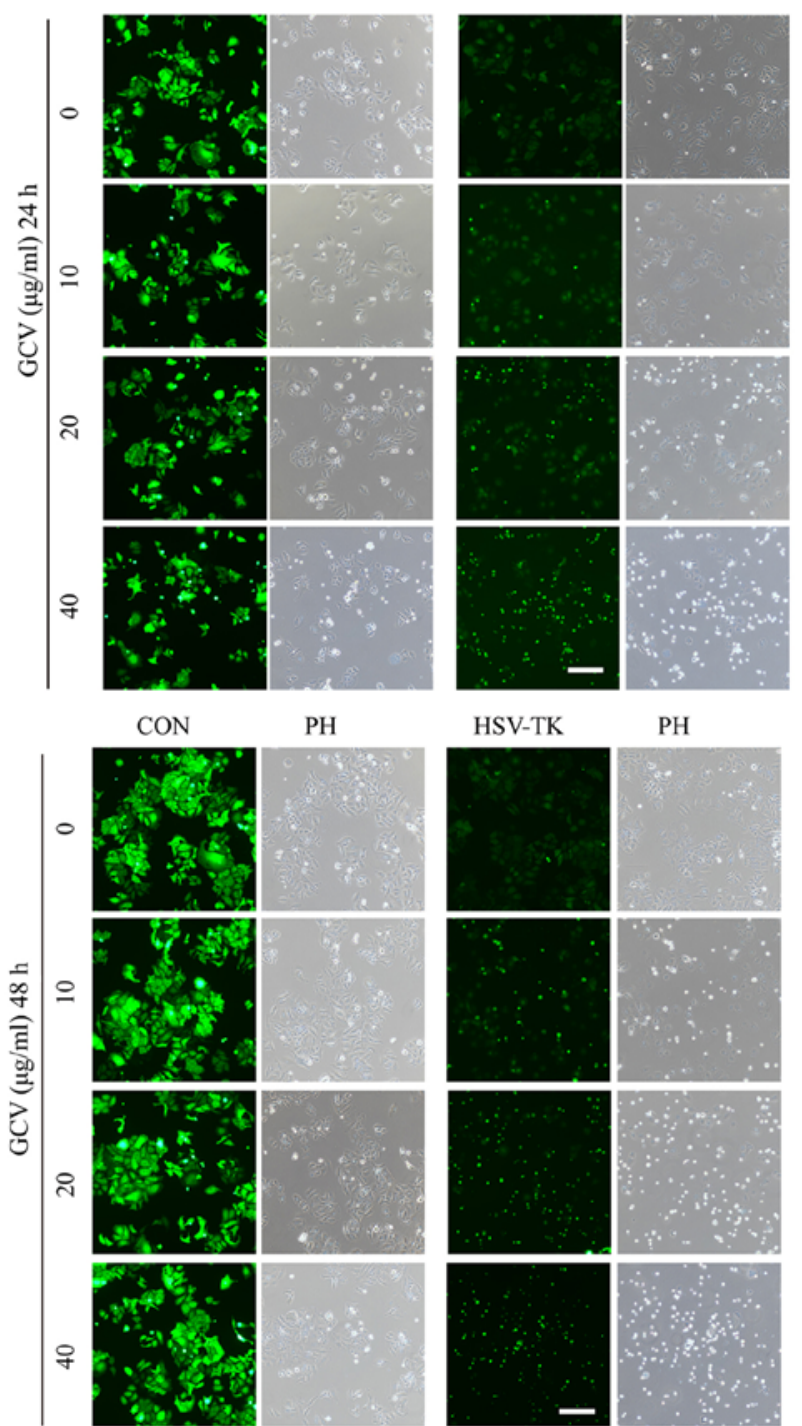

HSV-TK

PH
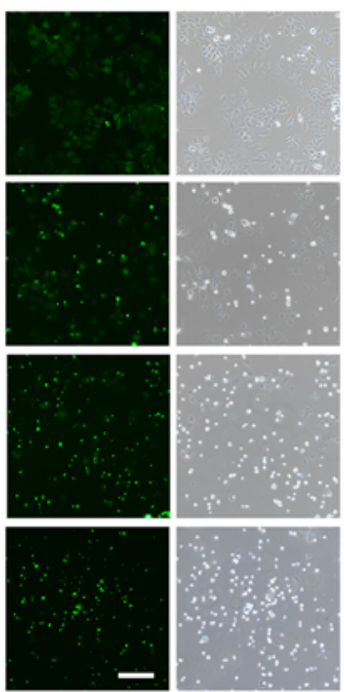

Figure 2. HSV-TK/GCV can significantly induce apoptosis of retinal tumor cells, as well as other tumor cells. (A) HSV-TK-positive (HSV-TK: pLenO-GTP-HSV-TK) or negative (CON: pLenO-GTP) HXO-RB44 cells were treated with GCV at $0,10,20 \mathrm{or} 40 \mu \mathrm{g} / \mathrm{ml}$ respectively. After $24 \mathrm{~h}$ posttransfection, cell viability was measured by MTT assay. (B) HSV-TK-positive (HSV-TK: pLenO-GTP-HSV-TK) or negative (CON: pLenO-GTP) HXO-RB44 cells were treated with GCV at $0,10,20$ or $40 \mu \mathrm{g} / \mathrm{ml}$, respectively for $48 \mathrm{~h}$. Cell viability was also measured by MTT assay. (C) Y79 cells transfected with CON or HSV-TK for $48 \mathrm{~h}$; cells were then treated with GCV at $20 \mu \mathrm{g} / \mathrm{m}$ for $48 \mathrm{~h}$. Cell viability were measured by MTT assay. (D and E) HeLa cells transfected CON (pLenO-GTP) or HSV-TK (pLenO-GTP-HSV-TK) for $48 \mathrm{~h}$, then the cells were treated with GCV at $0,10,20 \mathrm{or} 40 \mu \mathrm{g} / \mathrm{ml}$ respectively. Cell death was measured after 24 or $48 \mathrm{~h}$. The positive cells were colored green. The quantitative data are indicated as the means $\pm \mathrm{SD}$. ${ }^{\mathrm{P}}<0.05$, ${ }^{* *} \mathrm{P}<0.01$. NS, no significance; GCV, ganciclovir; HSV-TK, Herpes simplex virus type 1 thymidine kinase. 
A

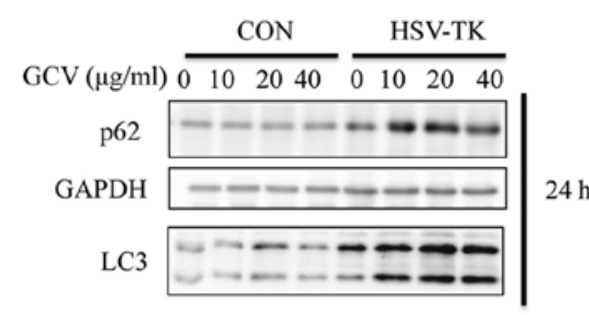

C

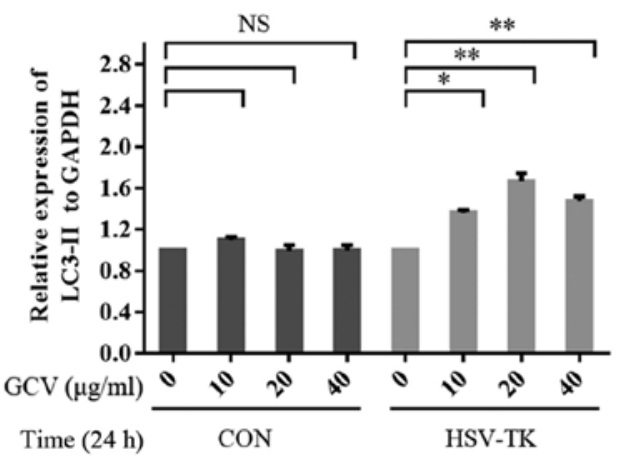

$\mathbf{E}$

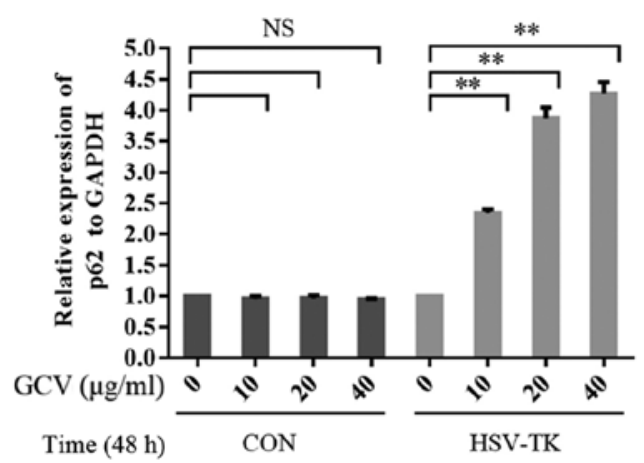

B

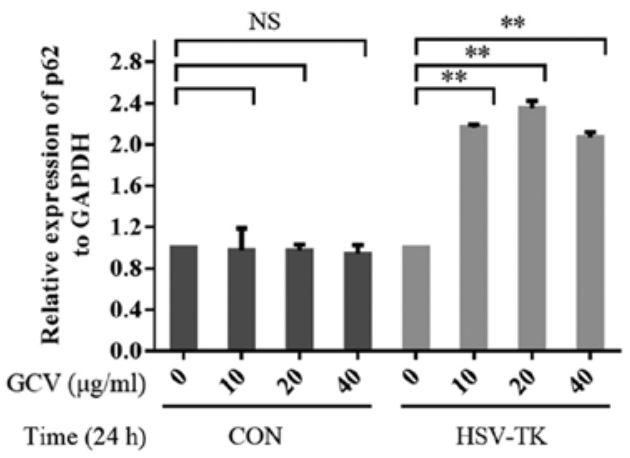

D

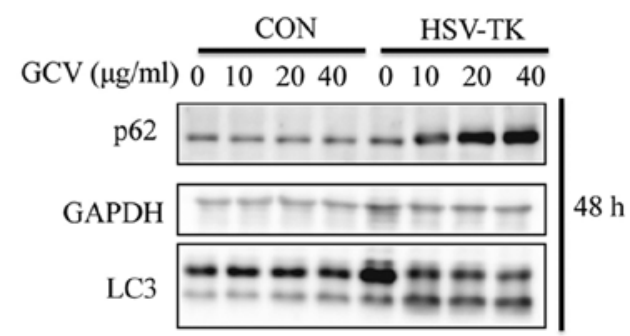

F

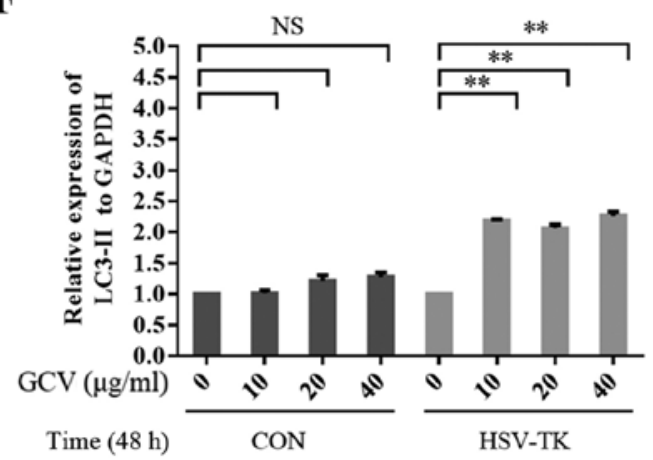

$\mathbf{G}$

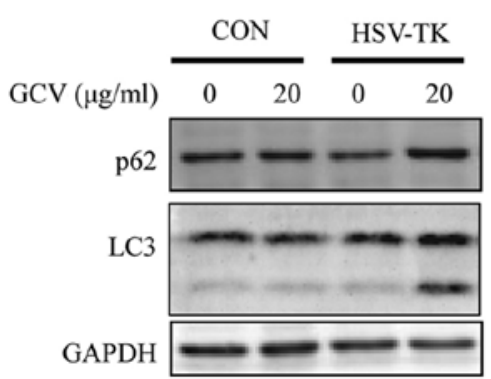

$\mathbf{H}$

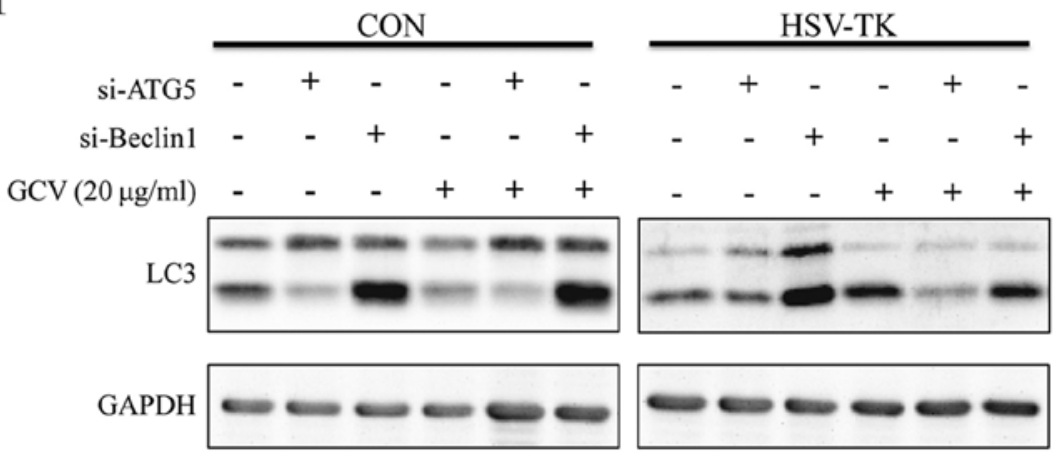

Figure 3. HSV-TK/GCV can upregulate autophagy-associated proteins. (A) CON (pLenO-GTP) or HSV-TK (pLenO-GTP-HSV-TK) were transfected to HXO-RB44 cells. After $48 \mathrm{~h}$ later the cells were incubated with GCV at $0,10,20$ or $40 \mu \mathrm{g} / \mathrm{ml}$, respectively for $24 \mathrm{~h}$. The cell lysates were then collected and subjected to immunoblotting. (B and C) p62 and LC3II expression levels in (A) were quantified. (D) HXO-RB44 cells transfected in the same manner as described in (A), and then treated with GCV at $0,10,20$ or $40 \mu \mathrm{g} / \mathrm{ml}$, respectively for $48 \mathrm{~h}$. The cell lysates were then collected and subjected to immunoblotting. (E and F) p62 and LC3II expression levels in (D) were quantified. (G) CON or HSV-TK were transfected to Y79 cells. After $48 \mathrm{~h}$ later the cells were incubated with GCV at $20 \mu \mathrm{g} / \mathrm{ml}$ for $48 \mathrm{~h}$. The cell lysates were then collected and subjected to immunoblotting. (H) The protein levels from three independent experiments were quantified. The quantitative data are indicated as the means \pm SD. NS, no significance, ${ }^{*} \mathrm{P}<0.05,{ }^{* *} \mathrm{P}<0.01$. GCV, ganciclovir; HSV-TK, Herpes simplex virus type 1 thymidine kinase. 
A

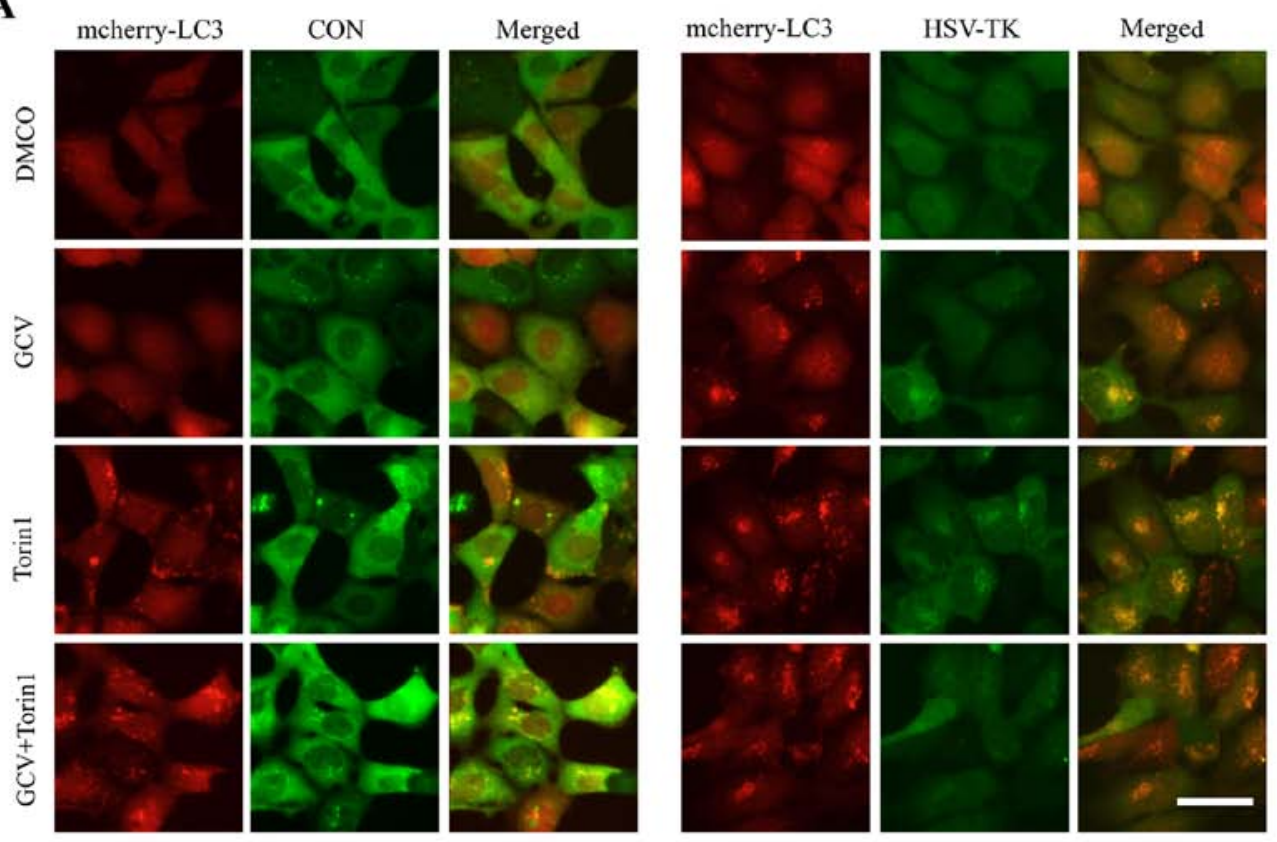

B

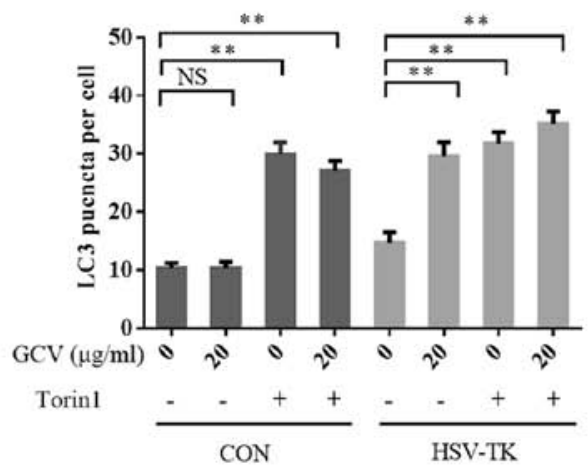

C

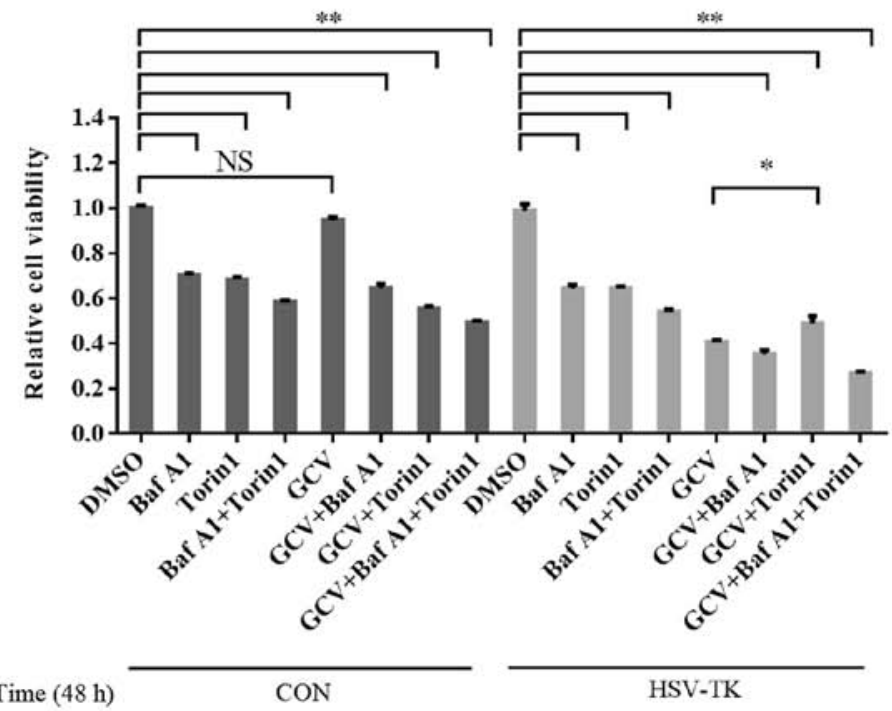

Figure 4. (A) 293 cells co-transfected with mcherry-LC3 (the positive cells colored red) and CON or HSV-TK (the positive cells colored green) for 48 h and then incubated with GCV at 0 or $20 \mu \mathrm{g} / \mathrm{ml}$ respectively for $48 \mathrm{~h}$. The scale bars indicate $20 \mu \mathrm{m}$. (B) Bar graph indicates that the average numbers \pm SD of LC3 puncta per cell were quantified by analyzing 100 cells per sample. (C) Pretreated HSV-TK positive HXO-RB44 cells with Torin1 (250 nM) or Baf A1 (100 nM) for $12 \mathrm{~h}$, and subsequently treated with GCV at $20 \mu \mathrm{g} / \mathrm{ml}$ for $48 \mathrm{~h}$. Cell viability was measured by MTT assay. Three independent experiments were performed. ${ }^{*} \mathrm{P}<0.05,{ }^{* *} \mathrm{P}<0.01$. GCV, ganciclovir; HSV-TK, Herpes simplex virus type 1 thymidine kinase; NS, no significance.

similar results. However, knockdown ATG5 or Beclin1 in HXO-RB44 cells which were HSV-TK negative did not affect LC3II expression levels regardless of whether GCV was administered or not (Fig. 3H). By manipulating autophagic flux, the present study reported that HSV-TK/GCV-induced cytotoxicity maybe mediated by inhibiting autophagy. To further observe HSV-TK/GCV-associated effects on autophagy, HSV-TK and mcherry-LC3 were co-transfected into 293 cells, which were then treated with GCV for $48 \mathrm{~h}$ at $10 \mu \mathrm{g} / \mathrm{ml}$. It was observed that LC3 aggregation increased significantly (Fig. 4A and B), indicating that autophagy was affected. Torin1 activates autophagy via the inhibition of mTOR. While pretreated HSV-TK-positive HXO-RB44 cells with Torin1 (250 nM) for $12 \mathrm{~h}$, and then removed Torin 1 , subsequently treated with GCV, the results suggested that Torin1 may partly attenuate the reduced cell viability induced by HSV-TK/GCV (Fig. 4C). These results suggest that HSV-TK/GCV-inducing retinal tumor cell death may be mediated by inhibition of autophagy.

HSV-TK/GCV induces cell cytotoxicity by specifically activating MAPK/ERK to inhibit autophagy. To further explore the molecular mechanism of HSV-TK/GCV autophagy activation, autophagy-associated signaling pathways were investigated. mTOR serves a central role in the regulation of autophagy (48). When HSV-TK-positive HXO-RB44 cells were treated with $20 \mu \mathrm{g} / \mathrm{ml} \mathrm{GCV}$ for $48 \mathrm{~h}$, the results 
A

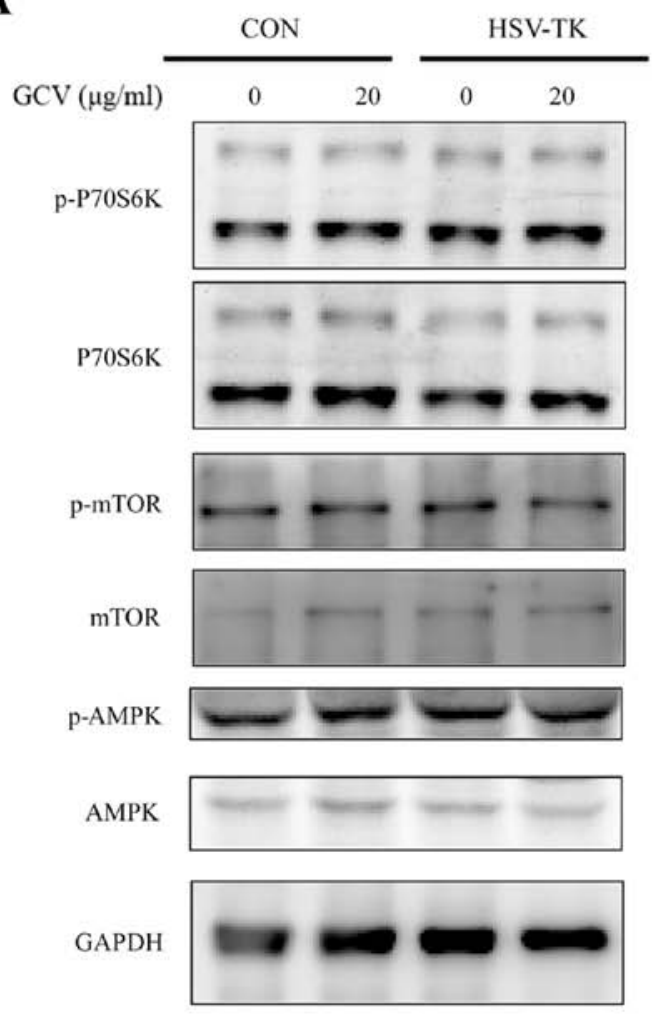

B
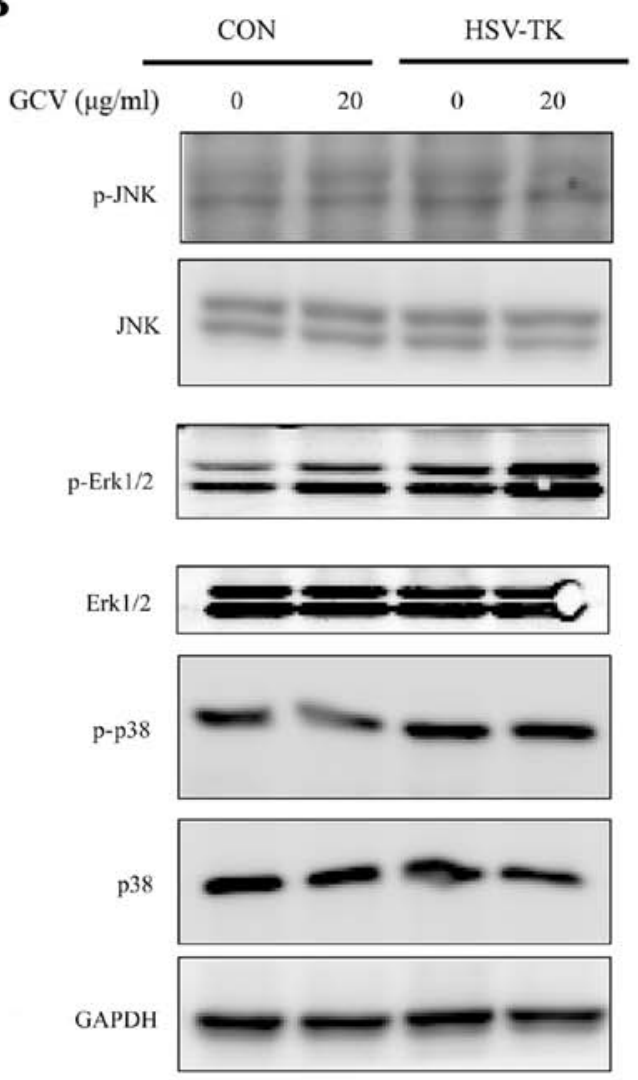

D

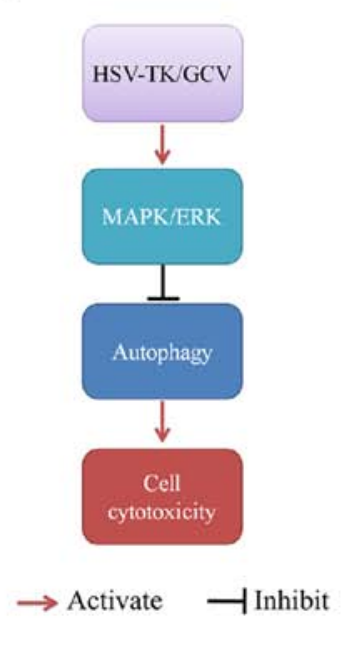

Figure 5. HSV-TK/GCV induced cell death possibly by specifically activating MAPK/ERK to inhibit autophagy. (A) HSV-TK-positive HXO-RB44 cells treated with GCV at 0 or $20 \mu \mathrm{g} / \mathrm{ml}$ for $48 \mathrm{~h}$. The cell lysates were then collected and subjected to immunoblotting with antibodies against the indicated proteins. (B) HSV-TK-positive HXO-RB44 cells treated with GCV in the same manner as described in (A). The samples from the cell lysates were subjected to immunoblot analysis to investigate the MAPK signaling pathways. (C) HSV-TK-positive or HSV-TK-negative HXO-RB44 cells pretreated with or without U0126 $(10 \mu \mathrm{M})$ for 4 and $48 \mathrm{~h}$ later, cell viability was measured by MTT assay. (D) The model of HSV-TK/GCV induced cell cytotoxicity by inhibiting autophagy. GCV, ganciclovir; HSV-TK, Herpes simplex virus type 1 thymidine kinase.

indicated that compared with in nontransfected cells, GCV treatment or transfection with HSV-TK but without GCV treatment exhibited no significant changes in phospho-mTOR and P70S6K substrate levels, suggesting that HSV-TK /GCV may not affect autophagy through the mTOR signaling pathway (Fig. 5A).
MAPK plays an important role in maintaining cell functions, such as cell proliferation (49), growth and differentiation $(50,51)$, and other functions (52). Many studies have also reported that MAPK is closely related to autophagy $(41,53,54)$. The results of the present showed that the levels of phosphorylated ERK were significantly 
upregulated in HXO-RB44 cells transfected with HSV-TK and treated with GCV, compared with in the groups without transfection treated with GCV or with transfection but without GCV treatment. Other MAPK-associated signaling pathways, including p38 and JNK, did not significantly change (Fig. 5B). Similar results were observed in the Y79 cells (data not shown). To further verify the findings of the present study, the MAPK/ERK signaling pathway was inhibited with U0126, a specific MEK inhibitor; whether cell cytotoxicity could be attenuated was investigated. The present study demonstrated that U0126 may partly but not completely attenuate reductions in cell viability (Fig. 5C). These results indicate that HSV-TK/GCV may induce cell death by inhibiting autophagy via specific MAPK/ERK activation (Fig. 5D).

\section{Discussion}

Numerous articles have previously reported that HSV-TK/GCV can significantly induce cell death in a variety of tumor cells; one of the underlying mechanisms for this cell death may induce apoptosis through inducing DNA damage $(18,21,37)$. However, the underlying molecular mechanisms have not been fully elucidated.

Autophagy is an important process within cells to maintain normal function. Cells can achieve energy reuse and self-renewal via the degradation of proteins and damaged organelles by autophagy $(22,23,25,30)$. Since the discovery of autophagy, researchers have found that its dysfunction is closely associated with numerous diseases, including cancer $(27-29,38)$. The HSV-TK/GCV system may also induce retinal tumor cell death; the present study reported that HSV-TK/GCV can induce significant death of two retinal tumor cell lines, HXO-RB44 and Y79, but also may induce other cell death, such as HeLa. The present study proposed that cell death may be mediated by affecting autophagy, and that LC3II and P62 are key components of autophagy. Our results suggested that LC3II and P62 expression levels of HXO-RB44 and Y79 cells were upregulated after transfection with HSV-TK and GCV treatment in a time- and dose-dependent manner. Manipulation of autophagic flux by knockdown ATG5 or Beclin1 revealed that LC3II of HSV-TK-positive HXO-RB44 cells treated with GCV decreased compared with the transfected group without GCV treatment. However, knockdown ATG5 or Beclin1 in HSV-TK negative HXO-RB44 cells indicated that LC3-II expression levels did not change in the presence or absence of GCV treatment. These results suggest that this cell death may mediated by the inhibition of autophagy. mTOR that plays a central role in the regulation of autophagy may inhibit autophagy by the phosphorylation of ATG13 $(30,55)$. Simultaneously, AMPK can also activate autophagy (56). Our results demonstrated that HSV-TK/GCV did not inhibit autophagy via the mTOR signaling pathway and did not affect AMPK activity (Fig. 5A).

MAPK is a mitogen-activated protein kinase, which can regulate cell growth and differentiation, as well as stress and inflammatory responses to the external environment, and other important cellular physiological/pathological processes $(28,50-52)$. It has been reported that MAPK also regulates autophagy signaling pathways $(41,54)$. The findings of the present study show that HSV-TK-positive retinal tumor cells were treated with GCV exhibited unaffected mTOR activity; the levels of their downstream substrate P70S6K did not change significantly (Fig. 5A). These results suggest that the HSV-TK/GCV system may not affect autophagy via the classical mTOR signaling pathway. In addition, the present study investigated whether AMPK, MAPK and other signal pathways were affected. The results demonstrated that the activities of AMPK, MAPK/P38 and MAPK/JNK were not significantly affected; however, phospho-ERK1/2 expression levels were upregulated (Fig. 5A and B). These results indicated that HSV-TK/GCV may reduce MAPK/ERK activity to activate autophagy and induce cell cytotoxicity.

Numerous studies have reported that the HSV-TK1/GCV system may block DNA chain elongation, leading to cell death $(11,18)$, and that the toxicity induced by HSV-TK/GCV may occur via apoptosis $(57,58)$. In the present study, the molecular mechanism underlying cell cytotoxicity to increase MAPK/ERK activity for the inhibition of autophagy was revealed. Additionally, activate autophagy through Torin1, an inhibitor of mTOR may partially, but not completely rescue cell cytotoxicity; however, in response to treatment with autophagy inhibitor Bafilomycine A1 and mTOR inhibitor Torin1, cell viability was significantly reduced compared with Torin1 or Baf A1 treatment alone (Fig. 4C). In addition, the effects of MAPK/ERK inhibitor may partly rescue cell cytotoxicity induced by the HSV-TL/GCV system (Fig. 5C), and may provide further support of the aforementioned results.

Cell cytotoxicity cannot be rescued by activating autophagy via treatment with Torin1, because HSV-TK/GCV may maximally inhibit autophagy, and cannot be reversed by Torin1, which itself has a certain cytotoxicity. The second reason is that autophagy is but one of the several ways that HSV-TK/GCV can induce cell cytotoxicity; however, the extent of the effects of autophagy on apoptosis is unclear. There are many reports that autophagy is closely related to cell apoptosis, and they even may be induced by common upstream signals (59). The inhibition of autophagy may induce cell apoptosis (59). Therefore, future research may investigate the association between autophagy and apoptosis in cell death induced by HSV-TK/GCV. At present, HSV-TK/GCV has been studied in numerous animals and in clinic (60-62). The rAAV-HSV-TK system has demonstrated inhibition of tumor cell growth with strong antitumor efficacy in mice models, and may be considered as a potential strategy for the treatment of bladder carcinoma (63). Similarly, as overserved in a mouse xenograft model of lung cancer, HSV-TK/GCV therapy may reduce tumor size (64). At the same time, HSV-TK was also demonstrated to be a promising mode of therapy in combination with other treatments (65). Few studies have reported that HSV-TK/GCV may induce retinal tumor cell toxicity; however, investigation has not been conducted within relevant animal models. The majority of the experiments in the present study were performed in vitro; further study is required to explore the molecular mechanism in vivo and clinical research of the association between HSV-TK/GCV for retinoblastoma may be conducted. In conclusion, the results suggested that further investigation into other mechanisms underlying HSV-TK/GCV-medicated cell cytotoxicity is required to develop treatments with increased therapeutic effectiveness. The findings of the present study regarding the effects of HSV-TK/GCV on 
autophagy may improve current understanding on its therapeutic mechanisms and contribute to research developments in clinical and non-clinical studies.

\section{Acknowledgements}

We thank Dr David Rubinsztein for providing us with the plasmids mCherry-hLC3B-pcDNA3.1.

\section{Funding}

The present study is supported by the Natural Science Foundation of Ningbo City (no. 2016A610014), and by the Projects of Medical and Health Technology Development program in Zhejiang province (no. 2017KY619).

\section{Availability of data and materials}

All data generated or analyzed in this study are included in this published article.

\section{Authors' contributions}

QYY, ZSB and BC carried out the research and data acquisition. ZSB drafted the manuscript and BC carried out the data analysis and statistical analysis. QYY designed the research, manuscript editing and manuscript review. NC, LSC, TY and HM also provided assistance for the acquisition and detection of cell samples. All authors read and approved the manuscript and agree to be accountable for all aspects of the research in ensuring that the accuracy or integrity of any part of the work are appropriately investigated and resolved.

\section{Ethics approval and consent to participate}

Not applicable.

\section{Consent for publication}

Not applicable.

\section{Competing interests}

The authors declare that they have no competing interests.

\section{References}

1. Abramson DH: Retinoblastoma in the 20th century: Past success and future challenges the Weisenfeld lecture. Invest Ophthalmol Vis Sci 46: 2683-2691, 2005.

2. Rodriguezgalindo C, Wilson MW, Chantada G, Fu L, Qaddoumi I, Antoneli C, Leal-Leal C, Sharma T, Barnoya M, Epelman S, et al: Retinoblastoma: One world, one vision. Pediatrics 122: e763-e770, 2008.

3. Bornfeld N, Schüler A, Bechrakis N, Henze G and Havers W: Preliminary results of primary chemotherapy in retinoblastoma. Klin Padiatr 209: 216-221, 1997.

4. Shields CL and Shields JA: Recent developments in the management of retinoblastoma. J Pediatr Ophthalmol Strabismus 36: 8-18; quiz 35-36, 1999.

5. Shields CL, Mashayekhi A, Cater J, Shelil A, Meadows AT and Shields JA: Chemoreduction for retinoblastoma: Analysis of tumor control and risks for recurrence in 457 tumors. Trans Am Ophthalmol Soc 102: 35-44, 2004.
6. Abramson DH, Dunkel IJ, Brodie SE, Kim JW and Gobin YP: A phase I/II study of direct intraarterial (ophthalmic artery) chemotherapy with melphalan for intraocular retinoblastoma initial results. Ophthalmology 115: 1398-1404, 2008.

7. ShieldsCLandShieldsJA:Retinoblastomamanagement: Advances in enucleation, intravenous chemoreduction, and intra-arterial chemotherapy. Curr Opin Ophthalmol 21: 203-212, 2010.

8. Rodriguez-Galindo C, Chantada GL, Haik BG and Wilson MW: Treatment of retinoblastoma: Current status and future perspectives. Curr Treat Options Neurol 9: 294-307, 2007.

9. Xu HJ, Zhou Y, Ji W, Perng GS, Kruzelock R, Kong CT, Bast RC, Mills GB, Li J and Hu SX: Reexpression of the retinoblastoma protein in tumor cells induces senescence and telomerase inhibition. Oncogene 15: 2589-2596, 1997.

10. Hayashi N, Ido E, Ohtsuki Y and Ueno H: An experimental application of gene therapy for human retinoblastoma. Invest Ophthalmol Vis Sci 40: 265-272, 1999.

11. Cullinan AE, Lindstrom MJ, Sabet S, Albert DM and Brandt CR: Evaluation of the antitumor effects of Herpes simplex virus lacking ribonucleotide reductase in a murine retinoblastoma model. Current Eye Res 29: 167-172, 2004.

12. Marshall E: Gene therapy a suspect in leukemia-like disease. Science 298: 34-35, 2002

13. Hossain JA, Ystaas LR, Mrdalj J, Välk K, Riecken K, Fehse B Bjerkvig R, Grønli J and Miletic H: Lentiviral HSV-Tk.007 mediated suicide gene therapy is not toxic for normal brain cells. J Gene Med 18: 234-243, 2016.

14. Howard BD, Boenicke L, Schniewind B, Henne-Bruns D and Kalthoff H: Transduction of human pancreatic tumor cells with vesicular stomatitis virus G-pseudotyped retroviral vectors containing a herpes simplex virus thymidine kinase mutant gene enhances bystander effects and sensitivity to ganciclovir. Cancer Gene Ther 7: 927-938, 2000.

15. Kenney S and Pagano JS: Viruses as oncolytic agents: A new age for 'therapeutic' viruses? J Natl Cancer Inst 86: 1185-1186, 1994.

16. Lou E: Oncolytic herpes viruses as a potential mechanism for cancer therapy. Acta Oncol 42: 660-671, 2003.

17. Moolten FL: Tumor chemosensitivity conferred by inserted herpes thymidine kinase genes: Paradigm for a prospective cancer control strategy. Cancer Res 46: 5276-5281, 1986.

18. Thust R: Ganciclovir-induced apoptosis in HSV-1 thymidine kinase expressing cells: Critical role of DNA breaks, Bcl-2 decline and caspase-9 activation. Oncogene 21: 2141-2153, 2002.

19. Beltinger C, Fulda S, Kammertoens T, Meyer E, Uckert W and Debatin KM: Herpes simplex virus thymidine kinase/ganciclovirinduced apoptosis involves ligand-independent death receptor aggregation and activation of caspases. P Natl Acad Sci USA 96: 8699-8704, 1999.

20. Wygoda MR, Wilson MR, Davis MA, Trosko JE, Rehemtulla A and Lawrence TS: Protection of herpes simplex virus thymidine kinase-transduced cells from ganciclovir-mediated cytotoxicity by bystander cells: The good samaritan effect. Cancer Res 57: 1699-1703, 1997.

21. Touraine RL, Ishiimorita H, Ramsey WJ and Blaese RM: The bystander effect in the HSVtk/ganciclovir system and its relationship to gap junctional communication. Gene Ther 5: 1705-1711, 1998.

22. Seino J, Wang L, Harada Y, Huang C, Ishii K, Mizushima N and Suzuki T: Basal autophagy is required for the efficient catabolism of sialyloligosaccharides. J Biol Chem 288: 26898-27907, 2013.

23. Kroemer G, Mariño G and Levine B: Autophagy and the integrated stress response. Mol Cell 40: 280-293, 2010.

24. Nakai A, Yamaguchi O, Takeda T, Higuchi Y, Hikoso S, Taniike M, Omiya S, Mizote I, Matsumura Y, Asahi M, et al: The role of autophagy in cardiomyocytes in the basal state and in response to hemodynamic stress. Nat Med 13: 619-624, 2007.

25. Mizushima N and Komatsu M: Autophagy: Renovation of cells and tissues. Cell 147: 728-741, 2011.

26. Tsukada M and Ohsumi Y: Isolation and characterization of autophagy-defective mutants of Saccharomyces cerevisiae. FEBS Lett 333: 169-174, 1993.

27. Menzies FM, Fleming A and Rubinsztein DC: Compromised autophagy and neurodegenerative diseases. Nat Rev Neurosci 16: 345-357, 2015.

28. Zhong Z, Sanchezlopez E and Karin M: Autophagy, inflammation and immunity: A troika governing cancer and its treatment. Cell 166: 288-298, 2016.

29. Shirakabe A, Ikeda Y, Sciarretta S,Zablocki DK and Sadoshima J: Aging and autophagy in the heart. Circ Res 118: 1563-1576, 2016.

30. Kim KH and Lee MS: Autophagy[mdash]a key player in cellular and body metabolism. Nat Rev Endocrinol 10: 322-337, 2014. 
31. Brech A, Ahlquist T, Lothe RA and Stenmark H: Autophagy in tumour suppression and promotion. Mol Oncol 3: 366-375, 2009.

32. Paglin S, Hollister T, Delohery T, Hackett N, McMahill M, Sphicas E, Domingo D and Yahalom J: A novel response of cancer cells to radiation involves autophagy and formation of acidic vesicles. Cancer Res 61: 439-444, 2001.

33. Macintosh RL, Timpson P, Thorburn J, Anderson KI, Thorburn A and Ryan KM: Inhibition of autophagy impairs tumor cell invasion in an organotypic model. Cell Cycle 11: 2022-2029, 2012.

34. Gavilán E, Sánchez-Aguayo I, Daza P and Ruano D: GSK-3 $\beta$ signaling determines autophagy activation in the breast tumor cell line MCF7 and inclusion formation in the non-tumor cell line MCF10A in response to proteasome inhibition. Cell Death Dis 4: e572, 2013.

35. Sun K, Guo XL, Zhao QD, Jing YY, Kou XR, Xie XQ, Zhou Y, Cai N, Gao L, Zhao X, et al: Paradoxical role of autophagy in the dysplastic and tumor-forming stages of hepatocarcinoma development in rats. Cell Death Dis 4: e501, 2013.

36. Colecchia D, Rossi M, Sasdelli F, Sanzone S, Strambi A and Chiariello M: MAPK15 mediates BCR-ABL1-induced autophagy and regulates oncogene-dependent cell proliferation and tumor formation. Autophagy 11: 1790-1802, 2015.

37. Jiang PD, Zhao YL, Shi W, Deng XQ, Xie G, Mao YQ, Li ZG, Zheng YZ, Yang SY and Wei YQ: Cell growth inhibition, $\mathrm{G}_{2} / \mathrm{M}$ cell cycle arrest, and apoptosis induced by chloroquine in human breast cancer cell line Bcap-37. Cell Physiol Biochem 22: 431-440, 2008.

38. Sasaki K, Tsuno NH, Sunami E, Tsurita G, Kawai K, Okaji Y, Nishikawa T, Shuno Y, Hongo K, Hiyoshi M, et al: Chloroquine potentiates the anti-cancer effect of 5-fluorouracil on colon cancer cells. Bmc Cancer 10: 370, 2010.

39. Maycotte P, Aryal S, Cummings CT, Thorburn J, Morgan MJ and Thorburn A: Chloroquine sensitizes breast cancer cells to chemotherapy independent of autophagy. Autophagy 8: 200-212, 2012.

40. Zou Y, Ling YH, Sironi J, Schwartz EL, Perezsoler R and Piperdi B: The autophagy inhibitor chloroquine overcomes the innate resistance of wild-type EGFR non-small-cell lung cancer cells to erlotinib. J Thorac Oncol 8: 693-702, 2013.

41. Kao C, Chao A, Tsai CL, Chuang WC, Huang WP, Chen GC, Lin CY, Wang TH, Wang HS and Lai CH: Bortezomib enhances cancer cell death by blocking the autophagic flux through stimulating ERK phosphorylation. Cell Death Dis 5: e1510, 2014.

42. Jahreiss L, Menzies FM and Rubinsztein DC: The itinerary of autophagosomes: From peripheral formation to kiss-and-run fusion with lysosomes. Traffic 9: 574-587, 2008

43. Fung C, Lock R, Gao S, Salas E and Debnath J: Induction of autophagy during extracellular matrix detachment promotes cell survival. Mol Biol Cell 19: 797-806, 2008.

44. Moscat J and Diazmeco MT: p62 at the crossroads of autophagy, apoptosis, and cancer. Cell 137: 1001-1004, 2009.

45. Zheng YT, Shahnazari S, Brech A, Lamark T, Johansen T and Brumell JH: The adaptor protein p62/SQSTM1 targets invading bacteria to the autophagy pathway. J Immunol 183: 5909-5916, 2009.

46. Komatsu M and Ichimura Y: Physiological significance of selective degradation of p62 by autophagy. FEBS Lett 584: 1374-1378, 2010.

47. Komatsu M, Kurokawa H, Waguri S, Taguchi K, Kobayashi A, Ichimura Y, Sou YS, Ueno I, Sakamoto A, Tong KI, et al: The selective autophagy substrate p62 activates the stress responsive transcription factor Nrf2 through inactivation of Keap1. Nat Cell Biol 12: 213-223, 2010.

48. Sancak Y, Peterson TR, Shaul YD, Lindquist RA, Thoreen CC, Bar-Peled L and Sabatini DM: The rag GTPases bind raptor and mediate amino acid signaling to mTORC1. Science 320 : 1496-1501, 2008.

49. Zhang W and Liu HT: MAPK signal pathways in the regulation of cell proliferation in mammalian cells. Cell Res 12: 9-18, 2002.

50. Ling MT, Wang X, Ouyang XS, Lee TK, Fan TY, Xu K, Tsao SW and Wong YC: Activation of MAPK signaling pathway is essential for Id-1 induced serum independent prostate cancer cell growth. Oncogene 21: 8498-8505, 2002.
51. Cui G, Qin X, Zhang Y, Gong Z, Ge B and Zang YQ: Berberine differentially modulates the activities of ERK, p38 MAPK, and JNK to suppress Th17 and Th1 T cell differentiation in type 1 diabetic mice. J Biol Chem 284: 28420-28429, 2009.

52. Hu Q, Li B, Xu R, Chen D, Mu C, Fei E and Wang G: The protease Omi cleaves the mitogen-activated protein kinase kinase MEK1 to inhibit microglial activation. Sci Signal 5: ra61, 2012.

53. Corcelle E, Djerbi N, Mari M, Nebout M, Fiorini C, Fénichel P, Hofman P, Poujeol P and Mograbi B: Control of the autophagy maturation step by the MAPK ERK and p38: Lessons from environmental carcinogens. Autophagy 3: 57-59, 2007.

54. Cagnol S and Chambard JC: ERK and cell death: Mechanisms of ERK-induced cell death - apoptosis, autophagy and senescence. FEBS J 277: 2-21, 2010.

55. Feng Y, He D, Yao Z and Klionsky DJ: The machinery of macroautophagy. Cell Res 24: 24, 2014

56. Kim J, Kundu M, Viollet B and Guan KL: AMPK and mTOR regulate autophagy through direct phosphorylation of Ulk1. Nat Cell Biol 13: 132-141, 2011.

57. Wei SJ, Chao Y, Hung YM, Lin WC, Yang DM, Shih YL, Ch'ang LY, Whang-Peng J and Yang WK: S- and G2-phase cell cycle arrests and apoptosis induced by ganciclovir in murine melanoma cells transduced with herpes simplex virus thymidine kinase. Exp Cell Res 241: 66-75, 1998.

58. Wei SJ, Chao Y, Shih YL, Yang DM, Hung YM and Yang WK: Involvement of Fas (CD95/APO-1) and Fas ligand in apoptosis induced by ganciclovir treatment of tumor cells transduced with herpes simplex virus thymidine kinase. Gene Ther 6: 420-431, 1999.

59. Maiuri MC, Zalckvar E, Kimchi A and Kroemer G: Self-eating and self-killing: crosstalk between autophagy and apoptosis. Nat Rev Mol Cell Biol 8: 741-752, 2007.

60. Gerolami R, Cardoso J, Lewin M, Bralet MP, Sa Cunha A, Clément O, Bréchot $\mathrm{C}$ and Tran PL: Evaluation of HSV-tk gene therapy in a rat model of chemically induced hepatocellular carcinoma by intratumoral and intrahepatic artery routes. Cancer Res 60: 993-1001, 2000

61. Rainov NG: A phase III clinical evaluation of herpes simplex virus type 1 thymidine kinase and ganciclovir gene therapy as an adjuvant to surgical resection and radiation in adults with previously untreated glioblastoma multiforme. Hum Gene Ther 11: 2389-2401, 2000.

62. Song JS and Kim HP: Adenovirus-mediated HSV-TK gene therapy using the human telomerase promoter induced apoptosis of small cell lung cancer cell line. Oncol Rep 12: 443-447, 2004

63. Pan JG, Zhou X, Luo R and Han RF: The adeno-associated virus-mediated HSV-TK/GCV suicide system: A potential strategy for the treatment of bladder carcinoma. Med Oncol 29: 1938-1947, 2012

64. Leinonen HM, Ruotsalainen AK, Määttä AM, Laitinen HM, Kuosmanen SM, Kansanen E, Pikkarainen JT, Lappalainen JP, Samaranayake H, Lesch HP, et al: Oxidative stress-regulated lentiviral $T K / G C V$ gene therapy for lung cancer treatment. Cancer Res 72: 6227-6235, 2012.

65. Colombo F, Barzon L, Franchin E, Pacenti M, Pinna V, Danieli D, Zanusso $\mathrm{M}$ and Palù G: Combined $H S V-T K / I L-2$ gene therapy in patients with recurrent glioblastoma multiforme: Biological and clinical results. Cancer Gene Ther 12: 835-848, 2005.

This work is licensed under a Creative Commons Attribution-NonCommercial-NoDerivatives 4.0 International (CC BY-NC-ND 4.0) License. 